\title{
Emotions and Dissonance in 'Ethical' Consumption Choices
}

\author{
Diana Gregory-Smith, Durham Business School, UK* \\ Andrew Smith, Nottingham University Business School, UK \\ Heidi Winklhofer, Nottingham University Business School, UK
}

* Correspondence should be addressed to: Diana Gregory-Smith, Durham Business School, Durham University, Queen's Campus, Stockton on Tees, TS17 6BH. Email: diana.gregory-smith@durham.ac.uk Telephone: +44 (0) 19133 40112. Fax: +44 (0) 1913340141 
Diana Gregory-Smith is a Lecturer in Marketing at Durham Business School. Her research interests lie in the area of consumer behaviour and psychology, particularly in relation to emotions and consumers' decision making. Current research projects are related to decision making in ethical consumption and pro-social marketing communications. She is also interested in decision making for tourism products.

Andrew Smith is an Associate Professor in Marketing at Nottingham University Business School. His principal areas of interest are consumer psychology and consumer time series data analysis. He has worked on a number of funded research projects for the ESRC, Scottish Office, European Union, The Office of Fair Trading and various commercial organisations.

Heidi Winklhofer is a Professor in Marketing at Nottingham University Business School with research interests in customer perceived value, customer participation, and contemporary marketing practice. She has worked with members of the Contemporary Marketing Practice group and various commercial organisations. Her current research deals with customers as effective resource integrators and measurements of customer value. 


\title{
Emotions and Dissonance in 'Ethical' Consumption Choices
}

\begin{abstract}
This paper investigates the role of emotions and the prevalence of dissonant/incongruent choice behaviour within the context of ethical consumption. Based on 31 in-depth interviews with British consumers, the findings demonstrate that consumers consciously indulge in 'ethical' and 'unethical' behaviour (as defined by respondents themselves), often within short time frames and that they often compensate for unethical choices by making ethical choices later on (and vice versa). The study provides evidence that positive and negative emotions are a key driver of this dissonant behaviour. Guilt is the most salient emotion and a taxonomy of guilt in this context is derived from the data. Consumers are found to employ guilt management strategies in order to sustain contradictory behaviour and manage cognitive dissonance. A conceptual framework is derived in order to summarise the observed role of emotions in ethical consumer choice. The paper also provides additional explanations of the manifestation of the attitude-behaviour gap.
\end{abstract}

Keywords: ethical consumption; dissonant behaviour; cognitive dissonance; emotions; attitudebehaviour gap 


\section{Introduction}

Previous studies about emotions have enhanced understanding of their influence in generic consumption decisions but various issues remain unaddressed. In much of the previous work, emotions are examined at a particular stage in the consumption process (e.g. Carrus, Passafaro, \& Bones, 2008 - anticipatory emotions; Allen et al., 2005 - immediate emotions; O’Guinn \& Faber, 1989 - post-decision emotions). There is still a need to comprehensively examine the interactions between various emotions experienced during different consumption episodes and at various stages of the consumption process. This is the essential aim of this paper: an exploration of the role of emotions in consumer choice, specifically in ethical consumption. The need for such an investigation is supported by previous research in psychology that has established that some emotions (e.g. guilt, shame) play a pivotal role in choices with a moral/ethical dimension (Haidt, 2003; Tangney, Stuewig, \& Mashek, 2007).

Prior research acknowledges that the 'genuine' ethical consumer is possibly a myth rather than a reality (Carrigan \& Attalla, 2001) and offers evidence for dissonant or inconsistent behaviour among ethically concerned consumers (McEachern et al., 2010; Szmigin, Carrigan, \& McEachern, 2009). However the manifestation of cognitive dissonance due to dissonant behaviour and the role

of emotions in these processes remain unexplored. The study reported here aims to address these limitations by providing insights into the sustenance of contradictory behaviour and cognitive dissonance, principally by exploring the role of emotion as a facilitator. 
Dissonant behaviour can be regarded as a manifestation of the attitude-behaviour gap and this gap has not been entirely explained in the context of ethical consumption although some explanations have shed light on how it is sustained (e.g. Chatzidakis et al., 2007). One potential explanation for this could also be the role of emotions in the decision making process. For example, it is possible that choice is driven by emotions (Elliott, 1998), and that these drivers can override expressed attitudes; this is an explanation addressed by this study. The findings presented here offer evidence for an emotion-driven choice, but they also provide new insights such as the compensatory process between ethical and unethical choices and a taxonomy that describes and explains the elicitation of guilt in choices with a moral dimension.

The findings of the present study suggest that emotions, cognition, incongruent behaviour and cognitive dissonance should not be explored independently but rather integrated and examined at different stages of the consumption cycle in order to allow an holistic understanding of consumers' decision making and the attitude-behaviour gap.

The results reported here have a number of managerial implications, particularly in the area of marketing communications. Firstly, advertising campaigns could be created to prompt different types of guilt, which entail different levels of intensity, according to the considered product and context. Secondly, counteracting strategies could be developed by marketers in response to guilt and regret management strategies employed by consumers. Finally, a significant practical implication is related to the use of positive emotions (e.g. pride, satisfaction, contentment) in encouraging ethical choice, especially in the case of those consumers who are not motivated to act ethically by negative emotions. 
The paper subsequently reviews the literature on ethical consumption, focusing particularly on the role of emotions in decision making, and the cognitive dissonance literature. The rationale for the research questions and the methodology are then discussed before the findings are presented. The paper concludes with a discussion of theoretical and practical implications.

\section{Emotions and decision making}

There is a significant body of literature dedicated to emotions in various areas of decision making and consumption. Basic emotions e.g. anger, regret, happiness, empathy have been studied across a range of subject disciplines such as economic theory, psychology and consumer behaviour, with studies examining aspects such as: emotions economic trade-off (Cryder et al., 2008), compulsive buying (O’Guinn \& Faber, 1989), self gift-giving (McKeage, 1992), product attitudes (Dube, Cervellon, \& Jingyuan, 2003), customer satisfaction (e.g. Westbrook \& Oliver, 1991) and loyalty (Bloemer \& de Ruyter, 1999). Emotions have also been found to play a role in managerial decisions with an ethical component (Connelly, Helton-Fauth, \& Mumford, 2004; Gaudine \& Thorne, 2001) thought the focus of the present research is on consumer decision making.

Compared to basic emotions, research dedicated to self-conscious emotions (SCEs - pride, guilt, embarrassment and shame) received less attention. Research about SCEs, both in generic and ethical consumption, is important because these emotions are regarded as being motivational. This is due to the process of self-evaluation which assumes a comparison between the actual self (and behaviour) and the 'ideal' self (Tracy \& Robins, 2004), or an evaluation based on inferences about others' opinions about how oneself should be and act like (Leary, 2004). In particular, shame and 
guilt are also influential due the moral appraisal that they involve by which they foster 'good' behaviour and hinder 'wrong' behaviour (Kroll \& Egan, 2004). Alternatively, pride can motivate ethical behaviour when choices are internalised as accomplishments (Tracy \& Robins, 2004).

Research about pride in consumption is rather limited and located around the concepts of promotion and prevention pride (Higgins et al., 2001), pride and product desirability (Griskevicius, Shiota, \& Nowlis, 2010) and, the effect of emotions on shopping satisfaction (Machleit \& Mantel, 2001). Negative SCEs were researched in relation to several contexts e.g. embarrassment and public self-consciousness in actual and future purchasing situations (Lau-Gesk \& Drolet, 2005); guilt and shame related to compulsive buying (O'Guinn \& Faber, 1989), shoplifting (Cox, Cox \& Moschis, 1990), and consumption and non-consumption of products such as training equipment and healthy food (Matta, Patrick \& MacInnis, 2005). The latter study showed consumers choose to dissipate negative feelings by acquiring or not acquiring specific products, but the study did not investigate how these individual episodes interact within a certain time frame, e.g. if they compensate each other in any way.

Another stream of literature looked at emotions and their influence on advert and brand/product evaluation, the general agreement being that emotions impact on attitude, intentions and actual purchase (e.g. happiness, sadness and mixed emotions - William \& Aaker, 2000; guilt and shame in pro-social attitudes - Bennett, 1998; fear and sadness in blood donation - Allen et al., 2005). Alternatively, social marketing studies have focused on guilt appeals in relation to volunteering (Dougherty, 1986), charity donations (Bozinoff \& Ghingold, 1983) and health products (Huhmann \& Brotherton, 1997). 
While these studies have enhanced understanding of the influence of emotions in generic consumption decisions various issues remain unaddressed. Some of the aforementioned studies offer a brief snapshot into consumers' choices (using methodologies such as surveys or experiments), and studied emotions during a particular consumption stage. These issues limit their ability to examine more complex dynamics of decision making and the potential interactions between various emotions experienced during different consumption episodes.

The next section will present a brief introduction into the ethical consumption literature, particular attention being paid to the existing literature about emotions.

\section{Ethical consumption and emotions}

Defining what ethical consumption is can lead the consumer researcher down a number of cul-desacs (Caruana, 2007). The term 'ethical consumption' incorporates an ethical/moral dimension, where the hedonic function and/or product utility are, to some extent, subordinated by concerns about right and wrong and consequences of consumption acts (Starr, 2009). Low and Davenport (2007) consider that ethical consumers have concerns in at least one of the following areas: human welfare, animal welfare and environmental welfare. In this paper, ethical consumption is defined by the consumers themselves and it refers to any of the abovementioned welfare areas, with consumers knowingly acknowledging the ethical dimension of their choice.

Various aspects of decision making and consumer characteristics have been researched in ethical consumption (e.g. ethical consumers' motivations - Megicks, Memery \& Williams, 2008; 
modelling of consumer rational decision making - Shaw, Shiu \& Clarke, 2000; and trade-offs for ethical choices - Cowe \& Williams, 2000). However, the studies dedicated to emotions are relatively few compared to the literature on emotions in generic decision making. Emotions were shown to influence cognitive variables involved in decision making. For example, Steenhaut and Kenhove (2006) have shown that idealism influences ethical belief through the mediation of anticipated guilt, with ethical belief predicting ethical intentions. Smith, Haugtvedt, and Petty (1994) demonstrated that affective reactions (i.e. 'guilt' and 'feeling good') in self-reported behaviour are correlated to recycling behaviour but they did not offer evidence for causal relationship. Carrus, Passafaro and Bonnes (2008) showed negative anticipatory emotions influencing intentions related to pro-environmental behaviour through the mediation of desire. However, by using an overall/index measurement of the influence of negative emotions, the study was not able to identify the discrete influence of each negative emotion (e.g. regret, guilt, sadness).

In other areas of ethical consumption emotions have often been presented as secondary findings. For example, Szmigin, Carrigan and McEachern (2009) briefly mention the interference of mood in decision making and feelings of discomfort associated with unethical choices. Guilt was also cited as a negative emotional outcome of unethical choices, in a study about ethical consumers and farmers' markets (McEachern et al., 2010). In Leonard-Barton and Rogers's (1980) classification of voluntary simplifiers, the category of consumers labelled as 'conformists' has been described as responding to guilt and peer pressure.

A more comprehensive study into the manifestation of guilt in generic consumption was conducted by Dahl, Honea and Manchanda (2003). Using consumer examples of guilt-inducing consumption choices, the authors classified guilt into three categories according to the generating circumstances 
- guilt related to others (i.e. in a close and distant relationship with others), guilt related to societal standards (i.e. violation of standards) and guilt related to oneself (i.e. achieving or contravening a personal consumption goal). In this study very few situations listed by consumers pertained to the ethical consumption area. Moreover, no difference in the severity of guilt was found across the three categories. While Dahl, Honea and Manchanda's (2003) classification seems to be applicable to different types of consumption choices, it can be regarded as too generic and unidimensional for the context of ethical consumption as it does not capture the particularities of this consumption area.

The issues and questions raised by these studies call for further investigation of the discrete impact of such emotions, both on intentions and behaviour, and also for a more in-depth examination of their manifestation in the context of ethical consumption.

\section{Cognitive dissonance}

Recent research in ethical consumption (McEachern et al., 2010; Szmigin, Carrigan, \& McEachern, 2009) suggests that dissonant or inconsistent behaviour is omnipresent. Consumers claim their behaviour is influenced by values and attitudes however, research has shown that values and attitudes do not necessarily translate into actual behaviour; this is the so called 'attitudebehaviour' gap (see for Chatzidakis, Hibbert \& Smith, 2007 for an overview). Inconsistent choices and attitude-behaviour gaps of consumers who engage in ethical consumption have also been briefly reported by earlier studies (e.g. Carrigan \& Attalla, 2001; De Pelsmacker, Driesen, \& Rayp, 2005; Schroder \& McEachern, 2004). A possible explanation for the attitude-behaviour gap is 
offered by the 'flexible' and 'dissonant behaviour' that ethical consumers adopt (McEachern et al., 2010; Szimigin, Carrigan, \& McEachern 2009). McEachern et al. (2010, p. 397) describe the dissonant behaviour of the conscious consumer using the term 'flexibility' which is 'the ability to change, adapt, and/or react to decision-making environments with little forfeiture of time, effort, cost, or product performance'. However there is a continued paucity of explanations for the attitude-behaviour gap in ethical consumption despite the fact that some explanations have been evidenced.

Behavioural dissonance, whether in generic or ethical consumption, is likely to come hand in hand with cognitive dissonance if consumers are conscious of their contradictory choices. It is feasible that the attitude-behaviour gap in ethical consumption is sustained because cognitive dissonance is somehow lived with. If negative emotions are outcomes of cognitive dissonance it is important to understand what role they play in the decision making process of future consumption episodes. Aronson et al. (1974) argue that the self-concept is critical in dissonance because each person is looking to conserve: a stable sense of self; a competent sense of self; and a morally good sense of self. In accordance with these views, it is likely that ethical consumption, due to its moral dimension, should be pertinent context for investigation. An examination of the literature on cognitive dissonance is required as a foundation for the investigation of the role played by emotions in ethical consumption dissonance and this is presented next.

The interest in cognitive dissonance commenced with Festinger's (1957) theory which states that dissonance arises when an individual holds two opposing or contradictory attitudes or beliefs. This leads to a negative, uncomfortable state that the person aims to reduce or eliminate. According to Aronson (1992, p. 305) 'dissonance is greatest and clearest when it involves not just any two 
cognitions but, rather, cognition about the self and a piece of our behaviour that violates that selfconcept'. The initial interest in cognitive dissonance gravitated around the cognitive dimension of the process. Subsequent research focused on the emotional/psychological manifestation of dissonance and started to include non-cognitive descriptors such as anxiety (Hunt, 1970), psychological discomfort (Elliot \& Devine, 1994), the general term of 'emotions' (Montgomery \& Barnes, 1993), uncertainty or doubt (Menasco \& Hawkins, 1978), regret and remorse (Insko \& Schopler, 1972). Elliot and Devine's (1994) induced-compliance experiment measured the psychological discomfort of dissonance using a range of items that were essentially emotional. The need to extend research into emotional outcomes of cognitive dissonance was highlighted by Elliott and Devine (1994) who acknowledged that in situations with higher self-relevance consumers could experience a wider range of emotions. In the same line of thought, Devine et al. (1991) asserted that the infringement of highly-internalised and self-defining standards can lead the individual to experience both discomfort and self-directed aversiveness (such as guilt and selfcriticism) but they did not explore this viewpoint. More recently, Sweeney, Hausknecht and Soutar (2000) proposed a measurement of cognitive dissonance that includes three dimensions i.e. emotional (e.g. angry, disappointed with myself, annoyed with myself, frustrated etc.), wisdom of purchase and concern over deal.

Other researched aspects of dissonance are related to its arousal and continuity. Koller and Salzberger (2007) have shown that in the context of package tours, cognitive dissonance can arise even in the pre-decision and pre-purchase phase, but dissonance was more evident and stable in the after-purchase stage. Oliver (1997) also acknowledges dissonance cannot be reduced only to a post-purchase or pre-use phase but rather it could never disappear. Research has also demonstrated 
that individuals strive to reduce or eliminate dissonance using a range of strategies: search for consonant information (Adams, 1961; Engel, 1963), distortion of provided information that is inharmonious with behaviour or purchase (Kassarjian \& Cohen, 1965), perceptual distortion (Janis \& Mann, 1977; Steinbruner, 1974), attitude change, opinion change (see Oshikawa, 1969), or avoidance of dissonant information (Frey, 1982). These dissonance reduction strategies can be regarded as highly cognitive strategies since reasoning guides a series of processes of search, distortion and change.

While the literature on cognitive dissonance makes reference to strategies meant to reduce the psychological emotional discomfort resulting from a conflicting choice, the psychology literature raises the possibility of emotion regulation strategies (e.g. Gross \& Thompson, 2007) and coping strategies (e.g. Dahl, Honea, \& Manchanda, 2003; Lazarus, 1991; Silfver, 2007). These choices do not necessarily imply opposing cognitions, like in the case of cognitive dissonance, and they can be relevant across a range of decision making situations including consumption-related ones. This concept was partially theorised in the consumption literature. For example, Elliott's (1998) theoretical framework of emotion driven choice suggests that consumers will try to eliminate negative emotions (e.g. guilt, regret, anxiety) through post-hoc rationality. However, this proposition has not been adequately explored by any empirical research in the field of ethical consumption, arguably its most pertinent application.

\section{Research objectives}


Despite the fact that studies such as those of McEarchern et al. (2010) and Carrigan and Attalla (2001) raise an important point about the inconsistency of behaviour among 'predominantly' ethical ('conscious') consumers, more evidence is required to explore the extent of dissonant behaviour and to probe the underlying psychology of such behaviour. In terms of justifications for unethical behaviour, Chatzidakis, Hibbert and Smith (2007) provided a list of rationalisations (neutralisations) employed to justify 'unethical' behaviour related to fair-trade products but there is a need to test the list of justifications and possibly to extend it to account for emotional influences. Furthermore, emotions are fundamentally non-rational and their impact may well help to explain how behavioural and cognitive dissonance are manifested and sustained. Emotions might even drive ethical behaviour or be more influential than attitudes (Elliott, 1998).

The specific objectives of this study are therefore:

1. To investigate the presence and the role of emotions in ethical decision making processes, with or without the presence of cognitive dissonance. The aim is to understand the holistic role of emotions and how they might facilitate dissonant behaviour and allow the attitudebehaviour gap to open up during specific episodes of purchase or consumption.

2. To provide more substantive evidence of dissonant/incongruent choice behaviour in an ethical consumption context with a varied cohort of respondents.

\section{Methodology}


The wide scope of the core research objective (Objective 1) inclined the research toward adopting an inductive approach based on in-depth interviews. Interviews were considered appropriate as experimental research focusing on dissonance has been criticised in the past for not offering realistic insights, because these studies were often based on student samples and used the 'forcedcompliance paradigm' (see Oliver, 1997; Oshikawa, 1969, 1970; Soutar \& Sweeney, 2003). It was hoped that interviews would also reduce the risk of social desirability bias (Belk, Devinney, \& Eckhardt, 2005).

Thirty-one interviews were undertaken in total. Interviews were conducted until thematic saturation was reached. Consumers who indicated they were never susceptible to ethically conscious behaviour or ethical considerations were excluded from the research. The cohort comprised respondents from a broad range of backgrounds with all interviewees having attended higher education. Respondents were recruited through social networks in the UK between January and April 2010. The cohort was balanced in terms of gender and the age ranged from 19-55 years; although the majority of the interviewees were in the age group of 25-40 years. Older interviewees were not recruited because of the nature of the employed sample, i.e. a convenience snowball sample. The majority of the participants could be classified as middle-class, in full-time and parttime employment with job descriptions as diverse as secretary, doctor, teacher, IT technician, lawyer, middle manager, and social care assistant. The average salary in the sample was slightly above the national average but consumers who buy 'ethical' products tend to be in the higher socioeconomic categories. 
The selection of the interviewees was not made on the basis of strong ethical orientation. The aim was to engage with consumers that vary in their magnitude of ethical orientation and who displayed both ethical and unethical behaviour over a period of time. The size of the cohort compares favourably to other related studies (e.g. Szmigin, Carrigan, \& McEachern, 2009; McEarchern et al., 2010). Moreover these previous studies relied on the account of consumers classified as 'primarily ethical consumers' or 'conscious consumers'. However, McDonald et al. (2006) argue a large number of consumers lay in the middle as 'beginner voluntary simplifiers' ${ }^{\prime}$. By investigating more thoroughly the dissonant behaviour of the 'more' and 'less' ethical consumers we can obtain a more realistic picture of how ethical products and services are consumed.

The interview guide was designed to be flexible (Kvale, 1983; O'Guinn \& Faber, 1989; Willis, 1990) and interviews were humanistic in nature i.e. they were as informal as possible and conducted in respondents' homes. A theoretical thematic analysis was employed in order to systematically code and analyse the data with the aim of identifying common patterns, metaphors, salient themes and, sub-themes (Thompson, 1997). These were then contrasted and considered with reference to the existing literature (see Braun \& Clarke, 2006). The results reported below include verbatim extracts and some commentary to give a flavour of the interview findings. The discussion was based around the respondents' own recollection of ethical and unethical choice and their perceptions of what ethical consumption was.

\footnotetext{
${ }^{\dagger}$ Beginner voluntary simplifiers are consumers who embrace some types of ethical behaviour e.g. various fair-trade products and recycling but they do not base their lifestyle on the assumptions of sustainability and ethics as voluntary simplifiers do. Alternatively, non-voluntary simplifiers disregard the ethical dimension of the products and services that they purchase and consume (MacDonald et al., 2006).
} 


\section{Findings}

Dissonant behaviour as the norm for the 'more' and 'less' ethical consumers

Overall, the research suggested that the crude division of consumers into ethical and unethical or into 'committed ethical consumers' and 'passive consumers' (Carrigan \& Attalla, 2001) is questionable. The majority of the participants in the study could be placed in the 'grey area' of ethical consumption as they manifest a composite type of general behaviour, which includes both ethical and unethical choices. The data showed similarities with McEarchen et al's (2010) in terms of the areas of ethical behaviour in which consumers were most engaged, and the importance of other product features over ethical considerations. The present findings also offered a more detailed insight into the flexible and dissonant behaviour of ethical consumers. For example, Szmigin, Carrigan, \& McEachern (2007) found incongruent behaviour across different product categories such as buying fair trade food but not buying fair trade clothes, while the current findings show that this type of behaviour can even occur within the same product category (see F4 quote about buying food from Waitrose).

The need to justify dissonant behaviour

Many of the justifications offered by consumers were consistent with other previous research (e.g. Barnett, 2007; Belk, Devinney, \& Eckhardt. 2005; McEachern et al., 2010; Slater \& Miller, 2007) 
and could be classified according to neutralisation techniques (see Chatzidakis, Hibbert, \& Smith, 2007) i.e. 'appealing to higher loyalties' (e.g. quality, price), the 'law of the ledger' (see compensatory choices below) and 'denial of responsibility':

'...at the end of the day I'm here and this is ... it's a bit selfish but I'm here and this is my money. Ifeel sorry for them [workers] but if there’s a top in there that's ... a vest top in there that's $£ 3.50$, I would pay $£ 7.50$ for that in River Island or more, so obviously I will buy the cheaper one. '(F10 $)$

In addition to supporting existing findings the present study highlighted new justifications related to the temporal element and the influence of affect (i.e. mood and emotions; see F3) and compensatory choices which are detailed below in two distinct sections.

'I guess again [depends] on what kind of mood I'm in. You know...righteous, like I should be doing the right thing, then I'd feel very guilty about it and at times I don't necessarily think about it. It depends again on what you're buying and the context of when you're buying it.' (F3)

Compensatory choices in ethical consumption

While findings of previous research show that 'ethical' consumers are positively motivated by moral values, and unethical consumers lack these values, or do not include them in their decision-

\footnotetext{
* Throughout the paper the verbatim extracts have been coded using F (i.e. female) and M (i.e. male) followed by a number which was used for the researchers' own records.
} 
making (i.e. price, brands, quality take precedent over ethics), the analysis of the interviews provided an additional explanation. In the case of the composite consumers there was a need to compensate their unethical choices with ethical ones (possibly a manifestation of the 'law of the ledger' - Chatzidakis, Hibbert, \& Smith, 2007). These compensatory actions were apparent in many categories and stages of consumption and disposal. The novel aspects of this compensatory process lie in the role played by emotions and in the discovery that compensation happens not only between different aspects of consumption (e.g. purchase versus recycling) but also within the same product category (e.g. food).

Efforts were made to compensate 'unethical' actions by enacting 'ethical' choices in areas such as fair trade- 'I always buy fair trade and I'm doing my bit, so that is the feeling that lasts.' (F10) with the need to stifle the voice of their conscience: No, no because I don't buy a lot from those shops but the thought does cross my mind... But again, because I try to balance it by giving in a charitable way to specific charities... Or maybe it's saving ... or maybe it's my conscience ... pricking my conscience and saying I've got to do something and although I can't get at the actual source of what is happening to these people, at least hopefully I can try and divert some money into that country.' (F9)

Male consumers were more concerned about balancing their unethical purchases of technologyrelated devices. Charity-giving was regarded as a way of compensating for these purchases. The accumulation of products reflected the use of resources but this could be balanced if handed down to others: 'For example, if we were to get rid of a lot of DVDs or something like that, we probably 
... in the past, what we have done is actually given them to charity shops, which I suppose is sort of recycling.' (M7)

Air miles and carbon footprint tended to be compensated by the purchase of the fair trade option of the same product: 'We buy a lot of fair trade wine and fair trade tea and sugar and that sort of thing... We haven't really gone down the road of the whole air mile thing' (F16).

Additionally, when price is a constraint in the purchase of only ethically produced goods, compensation can happen even inside the same category of products such as food:

'So we go to the big supermarkets if we're buying things like tins of baked beans or washing-up liquid or whatever. But our meat and our fruit and vegetables tend to come from Waitrose.... some companies have probably a more responsible attitude towards their sources of food and I think that Waitrose have demonstrated that.' (F4)

The role of emotions

Emotions were identified as both outcomes and generators of ethical/unethical behaviour, with a clear role in the process of compensatory choices. In other words positive emotions encourage future ethical consumption while negative emotions delay or restrain consumers from making unethical choices. In the following paragraphs, positive emotions are discussed first. They are followed by an exemplification of the compensatory process at the emotional level and by a section dedicated to negative emotions for which findings were richer. 
In the case of positive emotions opposing hedonic functions were identified. The first hedonic function relates to the outcome of ethical consumption. Some consumers actively sought purchase scenarios likely to engender emotions such as feeling good, feeling pleased, excitement, pride, and happiness. The uplifting associations that positive emotions generate are salient in the ethical consumers' mind and call them back to the same shops, fostering repeat ethical behaviour that will subsequently trigger more positive emotions. Some of these consumers also rejoiced the purchase of a cheap product or bargain and the positive emotions it encourages. These two types of hedonistic function appear to cohabit as a number of individuals admitted deriving positive emotional feedback from a purchase based on ethics or economics. They were often aware that a purchase driven by economics might be ethically questionable. Consumers' accounts showed that even the 'more conscious' consumers oscillated between emotions that generate a type of 'unethical hedonism' and emotions that produce a sort of 'ethical hedonism'. However, the findings suggest that any association with these hedonic categories goes beyond the shopping stage of consumption and incorporates disposal as well.

On several occasions it was revealed that these compensatory decisions rely on the emotional dimension of each choice. Some consumers make ethical choices because these lead to positive emotions, which compensate the negative emotions; or simply because they want to avoid negative emotions. This type of accounting which emerged from the data was labelled as 'emotional accounting' (see also Levav \& Mcgraw, 2009), to distinguish it from other types of accounting, or compensatory processes such as consumers' mental accounting (see Beruchashvili, Gentry, \& Price, 2006; Nisan, 1990). The extracts below show the dissonant behaviour of a male (M9) and 
female (F19) consumer and the way each of them uses emotions in the compensatory decision making process.

I've got a couple of things just down there, there's an old four-track recorder and mobile phone and I haven't thrown them away because they're not broken, they're just old. And I'd really like to see them being reused. So I suppose some of my guilt is mitigated by the fact that I like to pass things on to people wherever I possibly can and I use Freecycle you know, you can put things on there.' (M9) - guilt

\section{Versus:}

'Basically when I think about that, it does give me a kind of warm, fuzzy glow you know, it's like I've bought something... a wood burner...made from sustainable materials...made by disabled and disadvantaged people who'd been unemployed for a long time... that's not only going to be useful to me, it's like giving to charity at the same time. And that's something I feel positive about recently.' (M9) - contentment

Or:

'I guess I don't think it's quite feeling guilty, I don't think I'd feel guilty because it's more just like ... just not feeling very impressed with myself, not very proud of myself and sort of disappointed in myself [for not buying fair trade bananas because were 50p more expensive].' (F19) disappointment about oneself/shame

Versus: 
'Yeah, no, no I like ... I feel proud when we've only got one tiny little bag of rubbish (laughs) to be collected. Yeah, and I'm really pleased because we've started doing it at work as well and ... because so much rubbish was thrown away at work just in the main bin and that used to really upset me.' (F19) - pride

Negative emotions

More insights were highlighted when the interviewees discussed unethical choices (e.g. purchase of intensively farmed animal products; product disposal etc.) and their emotions at different stages i.e. before, during and after purchase.

For some consumers the purchase of other unethically produced items generated emotions such as feeling uncomfortable and guilt, and regret, feeling upset and disappointed. Other consumers confessed feelings of frustration, which were elicited by reflection on their product disposal patterns. A male consumer (M7) confessed: 'I don't think much about why I'm not recycling other stuff... [and this] makes me more frustrated'. (M7)

Most of the times shame was not experienced in isolation but rather in conjunction with regret and guilt (see F19 above). Embarrassment was less recurrent than shame or guilt and in the majority of cases was not verbally expressed but rather through physiological changes as observed by the interviewers.

'For instance, if you're telling me "Ok, so you're not going to go to conferences or holidays.... because of the implications of using [fuel and environmental concerns]...", I'll have a different 
view... Of course, you know, you don't want to make too much sacrifice obviously!. You know?

(embarrassed laugh).' (M10)

\section{Guilt}

The most negative salient emotion was guilt and it emerged in different areas of concern i.e. human welfare, animal welfare and environmental welfare.

Intensity of guilt
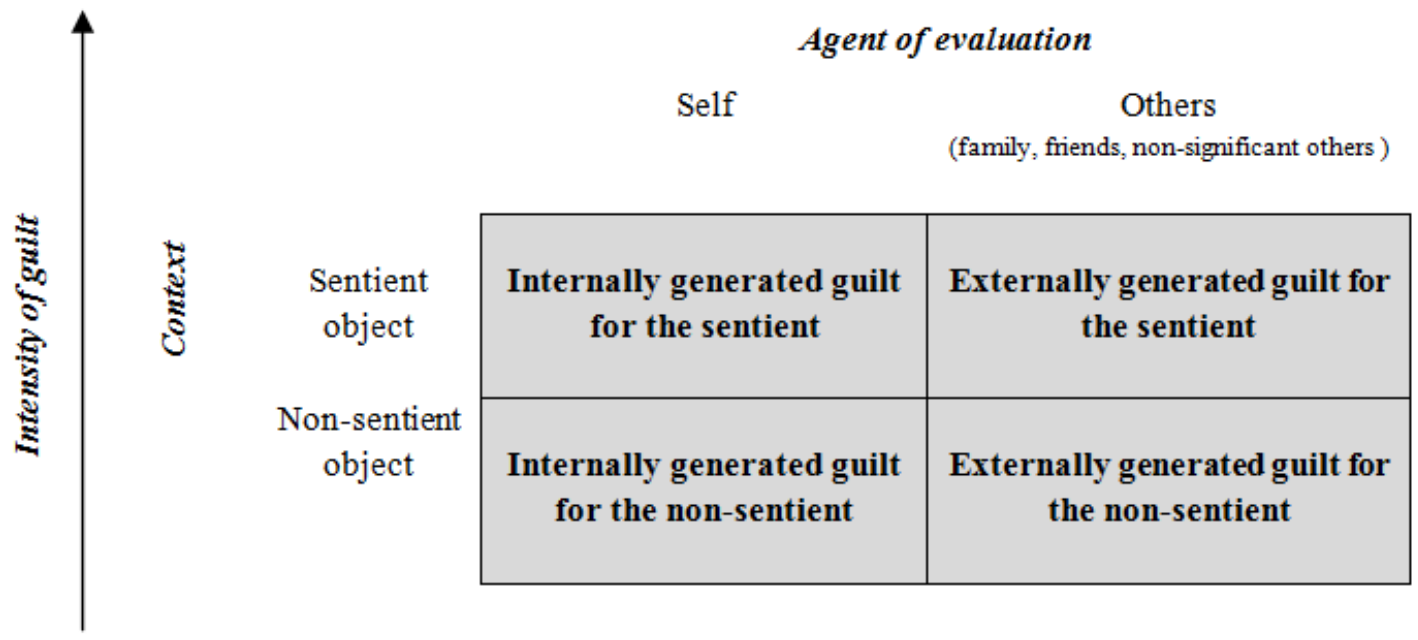

Figure 1. Taxonomy of guilt in ethical consumption

The data allowed the development of a guilt taxonomy (Figure 1) and a theory of how and why the intensity of guilt varies. In this matrix the categories of guilt are defined by two dimensions: context and agent of evaluation, while the third dimension, level of intensity, varies according to the first two dimensions. The context dimension describes whether beings or objects are perceived 
to be the victim. Guilt for the sentient is an extension of the present concept of existential guilt and extends the area of concern from only human beings to also include animals. Alternatively, guilt associated with environmental welfare in general, or other abstracts, was labelled as guilt for the non-sentient. The second dimension of the matrix shows that the agent of evaluation of a consumption act can be the self or others. Thus guilt could be elicited in two ways - internally and externally. Finally, the third dimension that characterises guilt in consumption is intensity. The intensity of guilt increases as the agent of evaluation moves on the horizontal axis from others to self and on the vertical axis from non-sentient object to sentient object. More specifically, on the horizontal axis the intensity of guilt generated by the evaluations of "others" (i.e. family, friends and non-significant others) is likely decreases according to the affective distance between the consumer and these three subcategories. This was also confirmed by the interviews. For some consumers different types of guilt can coexist even within the same consumption/disposal experience (see below extracts from F1's interview). So the most intense guilt was often induced by the self and driven by specific concerns for the welfare of humans or animals.

The findings pointed out that self-evaluation (i.e. based on one's standards and norms) determine a stronger and longer-lasting level of guilt than evaluations by others. However, the influence of others in the manifestation of guilt cannot be minimized; others' influence might be indirect but it is not necessarily secondary as illustrated in the verbatim extracts below.

'... it's that if I did buy say non-free-range eggs, from battery chickens or whatever, then I'd just feel bad.' (M9 - internally generated guilt for the sentient - animal welfare).

I got one very close girlfriend... So she is very strong. Every time she sees something on me she says "Ok, now you bought that! Just imagine where's been produced and stuff..." And I think my 
boyfriend also puts a lot of pressure on me. I get similar pressure from some members of my

family as well, yeah.' (F1 - externally generated guilt for the sentient - relating to sweat shops).

I put ... I think it was the wrong sort of packaging in the green bin, not the recycling bin but the normal rubbish bin and it could have been recycled and I hadn't. I now wash everything, tin cans, plastic food trays, I wash them out... [I felt] bad, bad, bad.' (M5 - internally generated guilt for the non-sentient - recycling).

I've got like my plastic bottle from my lunch or whatever, I probably would just chuck it in the bin rather than carry it around all day and then bring it home...I know people that would carry it around all day and everything, I'm not that good...then I come home and Chris has had a meal deal at lunchtime from Boots as well and his plastic bottle is sitting by the sink ready to be washed out to be recycled, it makes me think if he can do it, I should have done it really. So I guess it's really when Chris does something that reminds me I could have done it, that makes me feel a little bit like hmm ...!!' (F19 - externally generated guilt for the non-sentient - recycling).

The results confirmed Oliver's (1997) view that dissonance carries on beyond the post-purchase pre-use phase; this was particularly accurate in the case of guilt. The intensity of guilt seemed to change within the temporal framework according to different variables e.g. context, guilt management strategies, guilt proneness, internalised values, individual characteristics, and different ways of prioritising needs. For example, F1 describes the lifecycle of one of her guilt experiences as follows:

I feel like almost excitement kind of dominates the guilt after a while. You know if I feel like something I wear is not produced ethically, I feel guilty about it... but after the first day I wear it, 
I almost like internalise it and the guilt kind of goes away. It probably doesn't completely go away. It's probably still up there but it's not as intense.' (F1)

Alternatively, in the case of M7, guilt intensity increases with the value/cost of the product i.e. the more expensive the unethical product, the higher the intensity:

If I was going to feel bad about purchasing that sort of thing, it'd be about purchasing something... where I'm spending quite a reasonable amount of money on it, rather than necessarily smaller items that have still come from unethical sources, like tea or coffee.' (M7)

Regret and guilt management strategies

The present study confirmed consumers' use of previously identified dissonance reduction strategies, but more importantly it identified specific strategies that individuals employ in order to manage the most salient negative emotions that accompany dissonant behaviour - guilt and regret.

Firstly, consumers reported techniques used for managing regret. These included methods such as ignorance, justifications (e.g. limited ability to react in hindsight) and promises for improved future behaviour (see F18). Regret was experienced in relation to the disregard of ethical options, the prioritisation of convenience in consumption (F2) and the prioritisation of price/cost in shopping (F19).

'Yeah, it's just convenient. It's a horrible thing, isn't it?... So it's just a...it's a rule of thumb, it's like a shortcut, it's something you can do without...' (F2) 
The data has revealed specific ways of managing guilt in ethical consumption classified as: outcome/expediency oriented actions, introspection, diminishing net impacts, and the use of positive emotions.

In the case of outcome/expediency oriented actions consumers undertake purchases with a noticeable gain. Guilt is managed by emphasising one's need to accumulate some sort of returns, whether financial, emotional or social:

I feel a huge amount of guilt every time I take a plane but I just can't get over it; I just take it...because pretty much everyone I know or is close to me lives out of the UK. So I thought about it. The choices are to either move out of the UK or keep going back and forth and live with this guilt. So I'd probably take this option.' (F1)

Introspection was used by those consumers who were inclined towards reflecting on their emotional state in order to achieve emotional balance.

I guess if I think about it, then I feel guilty about it...

And did you try to escape the feeling of guilt in any way?

I just reflected on it and my actions. Then ... just accept it.' (F8)

Other consumers attempted to diminish net impacts by giving greater attention to the least harmful aspect of their choice. For each option consumers manage guilt by choosing to minimise the 
negative impacts and/or maximise the positive impacts, with positive impacts prompting positive emotions:

'We bought a carpet for our house a while ago and carpets are renowned for being toxic and having lots of implications on...environment, pollution implications from its production and actually I have no idea where that carpet was manufactured or anything. So I guess thinking about it you feel a little bit guilty about that. But on the plus side, the under layer of the carpet was made of recycled rubber and that made me feel good.' (F2)

The use of positive emotions represents another technique for counteracting guilt. In this case, consumers use hedonic feelings (M9), or generic positive emotions generated by imagined positive consequences to override guilt.

'And I eat it [sandwich made with non-free range eggs and meat] and I think I feel good because I'm eating something I enjoy and I just sort of push the guilt away (laughs) and forget about it. It's not like a horrible wrenching guilt like I've killed someone or something, it's just this little subtle feeling of guilt that I kind of have there. There's a kind of fuzzy cloud that I kind of sort of just push to one side and make it go away.' (M9) 


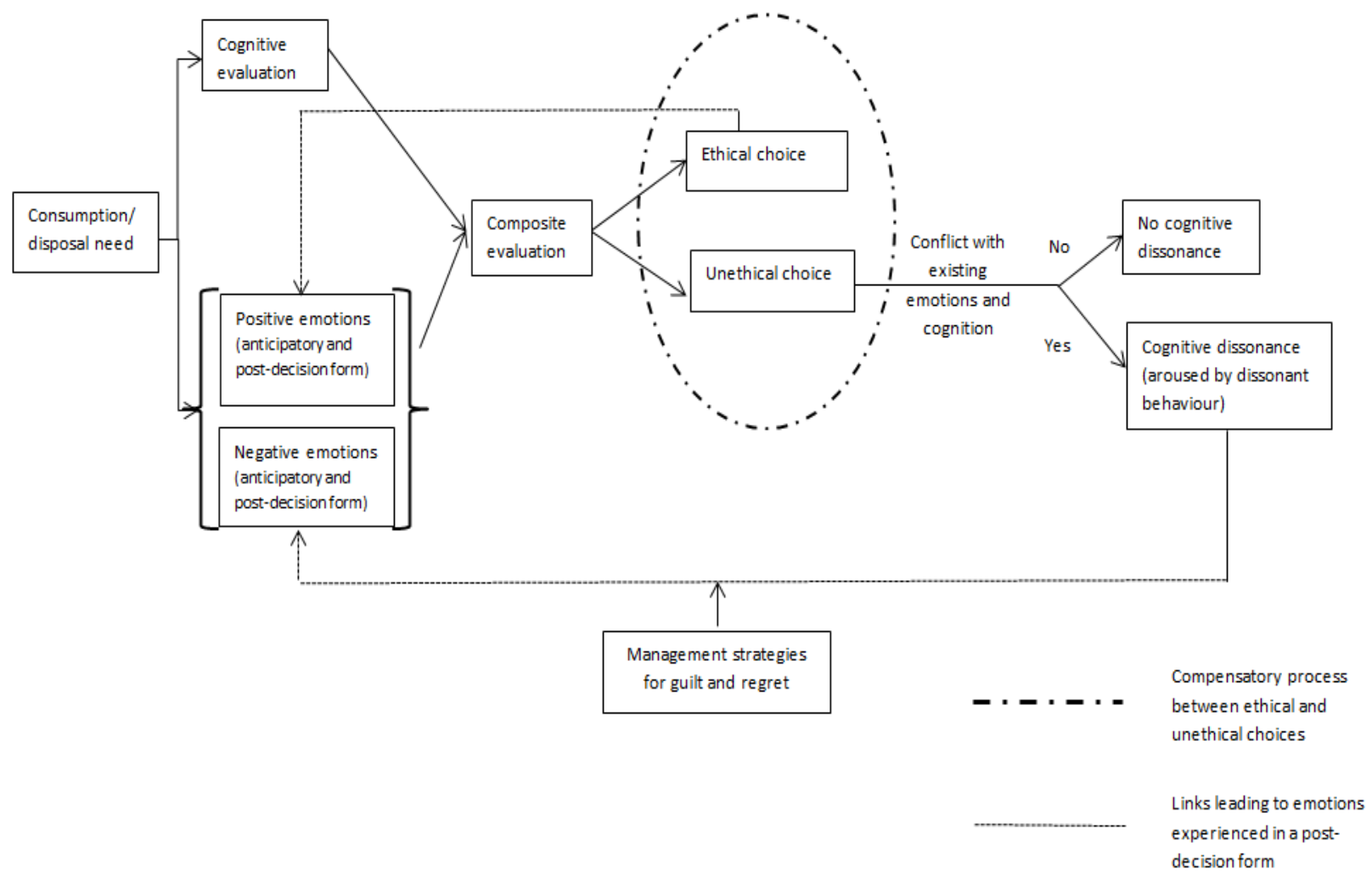

Figure 2: The influence of emotions on decision making in ethical consumption

The core findings of this research have been summarised in a theoretical framework that shows the role of emotions in consumers' decisions within the context of ethical consumption (see Figure 2). The framework indicates that once a consumption or disposal need occurs, two types of processes can arise - cognitive and affective, the latter being represented by anticipatory positive or negative emotions. These processes lead to a judgement which subsequently informs an ethical choice/unethical choice. If the individual opts for an unethical choice, which is not in conflict with existing emotions and cognition, then no cognitive dissonance arouses. If the consumer makes an ethical choice, positive post-decision emotions (e.g. pride, happiness) will be experienced. These 
emotions will reinforce the idea of making the 'right choice' and encourage similar ethical decisions in the future (i.e. in an anticipatory form).

Alternatively, if a consumer's evaluation results in a conflict, then cognitive dissonance emerges due to dissonant behaviour. Dissonance is usually accompanied by negative emotions in a postdecision form (e.g. guilt and regret) and consumers can employ management strategies to either reduce or eliminate these negative feelings. If these strategies are unsuccessful, then negative emotions are likely to influence future judgements in an anticipatory form i.e. the decision making process has a cyclical nature. Alternatively, if the negative emotions disappear, consumers will make similar unethical decision in the future and thus the 'attitude-behaviour' gap will be sustained over time. Finally, the framework shows individuals use a compensatory process which enables them to balance ethical and unethical choices. This process is responsible for both sustaining and bridging the 'attitude-behaviour' gap over a long period of time.

\section{Discussion}

Overall, the findings indicate that the application of any binary or simplistic classification of consumers as ethical or unethical is questionable, even fallacious. Self-conscious behaviour that is perceived to be ethical is context dependent more than person dependent. Within the varied cohort used in this research it was possible to identify all three types of consumers on the scale of voluntary simplicity (McDonald et al., 2006). The majority of consumers fell into the category of 'beginner voluntary simplifiers' as they displayed patterns of composite behaviour involving both ethical and unethical choices. 
Previous observations of consumers' justifications for inconsistent ethical behaviour were confirmed, but new explanations emerged from the data which enable a better understanding of how dissonant behaviour is sustained over time. As identified in this study, the need to compensate is also a manifestation of consumers' own awareness of their dissonant behaviour and the most salient manifestation of their need to justify this divergent behaviour. The current research also extends consumers' explanations and context of flexibility (Szmigin, Carrigan, \& McEachern, 2009) by identifying that individuals exhibit patterns of dissonant behaviour within the same area of concern/consumption (e.g. food products).

Regarding the 'attitude-behaviour' gap, our findings show that it is more accurately described as discontinuous behaviour that is sometimes in contradiction to underlying beliefs or instincts. More importantly, it was found that the magnitude of the gap is transitory and is a function of the temporal frame, context and, the ability to compensate choices and manage emotions, which will be discussed next. Firstly, in the context of ethical consumption, the gap can be explained by the positive impact of the hedonic emotions associated with the purchasing of bargains as well as situational factors and previously researched rationalisation strategies (Chatzidakis, Hibbert, \& Smith, 2007). However it is the discovery of the key role of emotional dimension that is most important.

Secondly, the findings revealed that the compensatory behaviour or consumers' mental accounting (as referred to by Beruchashvili, Gentry, \& Price, 2006; Nisan, 1990) can sometimes take a distinct form when guided by emotions i.e. emotional accounting. For example, the feeling of guilt related to an unethical consumption choice is compensated by contentment or pride associated with a 
preceding or subsequent ethical choice. This suggests that the compensatory process can explain the transitory nature of the 'attitude-behaviour' gap as ethical choices can bridge the gap, while unethical choices would determine the re-emergence of the gap.

Another key contribution concerns the decision making process and the interference of emotions. Emotions, such as pride, contentment, guilt, regret, shame and embarrassment, were shown to determine ethical choices. This contributes to the literature about emotions and ethical consumption, especially the area of environmental concern, by offering evidence of a discrete influence of each of these emotions on consumers' ethical intentions and choices, for which clear confirmation did not exist in previous research (see Carrus, Passafaro, \& Bonnes, 2008; Smith, Haugtvedt, \& Petty, 1994). Additionally, the guilt taxonomy presented here reflects via its dimensions the particularities of ethical consumption i.e. in terms of context, agent of evaluation and intensity. Furthermore, this taxonomy demonstrates the existence of various levels of guilt intensity which was refuted in Dahl, Honea and Manchanda's (2003) generic classification of guilt. The evidence for different types of guilt intensity levels shows how guilt can be regarded as a barometer for cognitive dissonance among consumers who display some ethical concerns.

The results about negative emotions support Sweeney, Hausknecht and Soutar's (2000) view that the emotional component of cognitive dissonance should include a large spectrum of feelings. While existing studies (e.g. Elliot \& Devine, 1994; Sweeney, Hausknecht, \& Soutar, 2000) did not capture or acknowledge the relevance of guilt and embarrassment, the present study has revealed that both self-conscious emotions are emotional manifestations of cognitive dissonance in the context of ethical consumption. Furthermore the present research has shown that consumers can experience different types of guilt with various levels of intensity and this has managerial 
implications for those concerned with consumers' dissonant behaviour. These linkages are depicted in the taxonomy of guilt which could form the basis of a theory that accounts for the variation in guilt intensity in ethical consumption, although this would require further research.

Another noteworthy finding of the study is the identification of strategies for managing regret and guilt (i.e. outcome/expediency oriented actions, introspection, diminishing net impacts, and the use of positive emotions). Some of these strategies demonstrate the relevance of Elliott's (1998) theoretical model which acknowledges consumers' use of post-hoc rationalisation in order to manage negative emotions. The guilt management strategy 'diminishing net impacts' by which consumers minimise the negative impacts and/or maximise the positive impacts of their choice is similar to the cognitive dissonance reduction strategy of 'perceptual distortion'. While both can be regarded as cognition-driven strategies, the guilt management strategy also entails an affective dimension as consumers highlighted positive emotions as outcomes and offered evidence for the positive impacts of their choice. Alternatively, the 'use of positive emotions' strategy can be principally regarded as an affect-driven strategy for managing guilt. Consumers use hedonic emotions generated by actual choice, or positive emotions generated by imagined positive consequences to manage guilt. These findings contribute to the literature about cognitive dissonance in two ways. Firstly, they have identified guilt management strategies specific to ethical consumption. Secondly, they have uncovered affect-driven strategies, involving positive emotions, in addition to cognition-driven strategies for managing guilt; these are not mentioned in extant literature about cognitive dissonance reduction strategies. 
All the aforementioned findings and contributions have been summarised in the theoretical framework (Figure 2). Overall, the framework presents a complex and dynamic process of decision making within which emotions and cognitive dissonance play key roles. The influence of positive and negative emotions extends beyond the post-decision stage, as they are shown to sway future decisions in an anticipatory form. Consumers experience negative emotions only when their unethical choice is in conflict with their degree of ethical orientation/cognition. As a result regret and guilt management are used in an attempt to reduce cognitive dissonance. At the same time, cognitive dissonance is managed via a compensatory process through which consumers balance their ethical and unethical choices, and resulting emotional outcomes.

\section{Conclusion}

\section{Managerial implications}

The findings showed both positive and negative emotions influence individuals' decisions in the context of ethical consumption. While previous research indicates that negative emotions can be effectively employed in marketing communications, it also acknowledges that with some consumers such appeals fail to register behavioural change (Brennan \& Binney, 2010). Evidence to explain the latter point was provided by the present study i.e. the guilt and regret management strategies. It is possible that marketing communications inducing positive emotions could be a successful alternative since consumers described satisfaction, contentment and pride as emotional rewards of their ethical choices. 
The guilt taxonomy presented here might be used to inform marketing communications encouraging ethical purchase/non-purchase or disposal i.e. guilt appeals. For example, in a campaign against generic environmental damage (an abstract) that wishes to illicit a high state of guilt, it might be wise to include a sentient signifier (a person or animal) as the basis of the image used (rather than a violated landscape). It also suggests that any campaign seeking to illicit higher levels of guilt should attempt to provoke the more 'private' state of guilt (see also Hibbert et al., 2007). The taxonomy might help marketing communicators to select appropriate signifiers whatever the level of guilt intensity required. Another implication is in terms of the advertising design as marketers can create adverts that prompt individual types of guilt, or a combination according to a particular segment's principal areas of concern i.e. human welfare, animal welfare or environmental welfare.

The existence of cognitive dissonance also has managerial implications in terms of marketing communications. However, how it is used and manipulated is a potentially problematic area in terms of ethics and practical mechanics. For example, a campaign might try to encourage the 'right' decision by portraying the resulting emotional dissonance (i.e. regret, guilt, shame, embarrassment) that one could experience when knowingly buying unethically produced products or services. Thus, there is a possibility that some consumers would 'switch off' when confronted with strong 'anticipatory' outcomes of cognitive dissonance. However, negative emotions could be presented as a warning sign and followed by a reminder of the outcomes and positive emotions entailed by an alternative choice i.e. the 'ethical' choice. 
Knowledge about how consumers manage their guilt is of use for marketers since counteracting strategies could be employed in other marketing communications i.e. strategies aimed at neutralising the techniques used by consumers to justify and sustain their less ethical behaviour. Whilst the study indicates how pro-social marketing communications might manipulate emotions, it also gives insights into how companies claiming to market 'ethical' products might exploit emotions (possibly to the detriment of the consumer).

A final implication is related to previously suggested segmentations of ethical consumers according to their degree of 'ethical' consciousness. McEachern et al. (2010) showed that 'conscious' consumers offer various justifications for their unethical choices (e.g. time, convenience, and price) and thus show signs of a 'flexile' behaviour. The present research reinforces the idea that dissonant and compensatory behaviour characterise both the 'more' and 'less' ethical consumers. Since all consumers, irrespective of the strength of their ethical orientation, show signs of compensatory behaviour and use of emotional management strategies, a segmentation according to their 'consciousness' might not be effective.

\section{Future research and limitations}

The findings should be interpreted in the light of the importance that consumers placed on certain areas of consumption and disposal. Future research needs to be conducted to substantiate these findings. A longitudinal study is probably required in order to monitor choice and behaviour over time, as the study reported here relies on the respondents' memory. Since the results showed that the same individual can behave completely different in a different context and that classifications 
or segmentations of consumers into categories such as 'ethical' and 'unethical' are not realistic, future research could investigate particular manifestations of consumer ethical/unethical behaviour in some of the contexts that were identified in the present study. The guilt taxonomy and the explanatory dimensions could also serve as basis for further research. Lastly, this is one study in one country and it relies on consumers' recall of their behaviour and of course the authors' interpretation.

\section{A final thought}

Overall, the current findings highlight the necessity of focusing on consumer decision making at an individual level given the multidimensional and miscellaneous behaviour of each consumer. The results highlight the complexity of decision making in ethical consumption and consumption more generally. As McDonald et al. (2006, p. 530) state 'consumption behaviour is unpredictable and heavily context dependent'. When the findings reported here are considered in conjunction with McEachern et al. (2010) and Chatzidakis, Hibbert and Smith (2007), then the debate about the attitude-behaviour gap in ethical choice becomes more enlightened. At the individual level the

gap is transitory; it comes and goes. It arises because of contextual factors, it is facilitated by rationalisation and the dissonant behaviour that gives rise to the gap which is often emotionally driven.

\section{References:}

Adams, J.S. (1961). Reduction of cognitive dissonance by seeking consonant information. The Journal of Abnormal and Social Psychology, 62(1), 74 - 78. 
Allen, C. T., Machleit, K.A., Kleine, S.S., \& Notani, A.S. (2005). A place for emotion in attitude models. Journal of Business Research, 58(4), 494-499.

Aronson, E. (1992). The return of the repressed: Dissonance theory makes a comeback. Psychological Inquiry, 3, 303-311.

Barnett, C. (2007). Governing the subjects and spaces of ethical consumption (ESRC End of Award Report, RES-143- 25-0022-A). Retrieved from

http://www.open.ac.uk/socialsciences/research/spaces-of-ethical-consumption.php

Belk, R.W., Devinney, T., \& Eckhardt, G. (2005). Consumer ethics across cultures. Consumption, Markets and Culture, 8(3), 275-289.

Bennett, R. (1998). Shame, guilt and responses to non-profit and public sector ads. International Journal of Advertising, 17, 483-499.

Beruchashvili, M., Gentry, J.W., \& Price, L.L. (2006). Striving to be good: Moral balance in consumer choice. Paper presented at the European Advances in Consumer Research, 7, 303-307.

Bloemer, J., \& de Ruyter, K. (1999). Customer loyalty in high and low involvement service settings: The moderating impact of positive emotions. Journal of Marketing Management, 15 (4), 315-330.

Bozinoff, L., \& Ghingold, M. (1983). Evaluating guilt arousing marketing communications. Journal of Business Research, 11(2), 243-255.

Braun, V., \& Clarke, V. (2006). Using thematic analysis in psychology. Qualitative Research in Psychology, 3, 77-101.

Brennan, L., \& Binney, W. (2010). Fear, guilt, and shame appeals in social marketing. Journal of Business Research, 63 (2), 140-146.

Carrigan, M., \& Attalla, A. (2001). The myth of the ethical consumer - Do ethics matter in purchase behaviour. Journal of Consumer Marketing, 18(7), 560-77.

Carrus, G., Passafaro, P., \& Bonnesa, M. (2008). Emotions, habits and rational choices in ecological behaviours: The case of recycling and use of public transportation. Journal of Environmental Psychology, 28(1), 51-62. 
Caruana, R. (2007). A sociological perspective of consumption morality. Journal of Consumer Behaviour, 6, 287-304.

Chatzidakis, A., Hibbert, S., \& Smith, A P. (2007). Why people don't take their concerns about fair trade to the supermarket: The role of neutralization. Journal of Business Ethics, 74, 89-100.

Connelly, S., Helton-Fauth, W., \& Mumford, M.D. (2004) A Managerial in-basket study of the impact of trait emotions on ethical choice. Journal of Business Ethics, 51(3), 245-267.

Cowe, R., \& Williams, S. (2000). Who are the ethical consumers?. The Cooperative Bank Report.

Cox, D., Cox, A.D., \& Moschis, G.P. (1990). When consumer behavior goes bad: An investigation of adolescent shoplifting. Journal of Consumer Research, 17(2), 149-159.

Cryder, C.E, Lerner, J.S, Gross, J.J., \& Dahl, R.E. (2008). Misery is not miserly: Sad and selffocused individuals spend more. Psychological Science, 19(6), 525-530.

Dahl, D.W, Honea, H., \& Manchanda, R.V. (2003). The nature of self-reported guilt in consumption contexts. Marketing Letters, 14(3), 159-171.

De Pelsmacker, P., Driesen, L., \& Rayp, G. (2005). Do consumers care about ethics? Willingness to pay for fair-trade coffee. Journal of Consumer Affairs, 39(2), 363-385.

Devine, P., Monteith, M., Zuwerink, J., \& Elliot, A. (1991). Prejudice with and without compunction. Journal of Personality and Social Psychology, 60, 817-830.

Dougherty, P.H. (1986, December 17). New spot for meals program. The New York Times, p.1.

Dube, L., Cervellona, M., \& Jingyuanb, H. (2003). Should consumer attitudes be reduced to their affective and cognitive bases? Validation of a hierarchical model. International Journal of Research in Marketing, 20(3), 259-272.

Elliott, R. (1998). A model of emotion-driven choice. Journal of Marketing Management, 14, 95108.

Elliot, A.J., \& Devine, P.G. (1994). On the motivational nature of cognitive dissonance: Dissonance as psychological discomfort. Journal of Personality and Social Psychology, 67, 382394.

Engel, J.F. (1963). Are automobile purchasers dissonant consumers?. Journal of Marketing, 27, $55-58$. 
Festinger, L. (1957). A theory of cognitive dissonance. Stanford: Stanford University Press

Frey, D. (1982). Different levels of cognitive dissonance, information seeking, and information avoidance. Journal of Personality and Social Psychology, 43(6), 1175-1183.

Gaudine, A., \& Thorne, L. (2001) Emotion and ethical decision-making in organizations, Journal of Business Ethics, 31(2), 175-187.

Griskevicius, V., Shiota, M.N., \& Nowlis, S.M. (2010). The many shades of rose-colored glasses: An evolutionary approach to the influence of different positive emotions. Journal of Consumer Research, 37, 238-250.

Gross, J.J., \& Thompson, R.A. (2007). Emotion regulation: Conceptual foundations. In J.J. Gross (Ed.), Handbook of emotion regulation (pp. 3-26). New York: Guilford Press.

Haidt, J. (2003). The moral emotions. In R. J. Davidson, K. R. Scherer, \& H. H. Goldsmith (Eds.), Handbook of affective sciences. Oxford: Oxford University Press (pp. 852-870).

Hibbert, S., Smith, A., Davies, A., \& Ireland, A. (2007). Guilt appeals: Persuasion knowledge and charitable giving. Psychology and Marketing, 24(8), 723-742.

Higgins, E.T., Friedman, R.S., Harlow, R.E., Idson, L.C., Ayduk, O.N, \& Taylor, A. (2001). Achievement orientations from subjective histories of success: Promotion pride versus prevention pride. European Journal of Social Psychology, 31, 3-23.

Huhmann, B.A., \& Brotherton, T.P. (1997). A content analysis of guilt appeals in popular magazine advertisements. Journal of Advertising, 26 (2), 35-45.

Hunt, S.D. (1970). Post-transaction communications and dissonance reduction. Journal of Marketing, 34, 46-51.

Insko, C.A., \& Schopler, J. (1972). Experimental social psychology: Text with illustrative readings. New York: Academic Press.

Janis, I.L., \& Mann, L. (1977). Decision making: A psychological analysis of conflict, choice, and commitment. New York, NY: Free Press.

Kassarjian, H.H., \& Cohen, J.B. (1965). Cognitive dissonance and consumer behavior. California Management Review, 55-64. 
Koller, M., \& Salzberger, T. (2007). Cognitive dissonance as a relevant construct throughout the decision-making and consumption process - an empirical investigation related to package tour. Journal of Customer Behaviour, 6(3), 217-227.

Kroll, J., \& Egan, E. (2004). Psychiatry, moral worry, and moral emotions. Journal of Psychiatric Practice, 10, 352-60.

Kvale, S. (1983). The qualitative research interview: A phenomenological and a hermeneutical mode of understanding. Journal of Phenomenological Psychology, 14(2), 171-196.

Lau-Gesk, L., \& Drolet, A. (2005). Public self-consciousness and purchase intentions for embarrassing products. Advances in Consumer Research, 32, 189-190.

Lazarus, R. (1991). Emotion and adaptation. New York: Oxford University Press.

Leary, M.R. (2004). Digging deeper: The fundamental nature of "self-conscious emotions". Psychological Inquiry, 15(2), 129-131.

Leonard-Barton, D., \& Rogers, E. (1980). Voluntary simplicity. Advances in Consumer Research, 7, 28-34.

Levav, J. \& Mcgraw, A.P. (2009). Emotional accounting: How feelings about money influence consumer choice. Journal of Marketing Research, 46(1), 66-80.

Low, W., \& Davenport, E. (2007). To boldly go. . .Exploring ethical spaces to re-politicise ethical consumption and fair trade. Journal of Consumer Behaviour, 6, 336-348.

Machleit, K.A., \& Mantel, S.P. (2001). Emotional response and shopping satisfaction: Moderating effects of shopper attributions, Journal of Business Research, 54 (2), 97-106.

Matta, S., Patrick, VM., \& MacInnis, DJ. (2005). Exploring shame and guilt in consumer behaviour. Advances in Consumer Research, 32, 191-192.

McDonald, S., Oates, C., Young, C.W., \& Hwang, K. (2006). Towards sustainable consumption: Researching beginner voluntary simplifiers. Psychology and Marketing, 23, 515-534.

McEachern, M.G., Warnaby, G. Carrigan, M., \& Szmigin, I. (2010). Thinking locally, acting globally? Conscious consumers and farmers' markets. Journal of Marketing Management, 26(5/6), 395-412. 
McKeage, K.K.R. (1992). Materialism and self-indulgences: Themes materialism in self-gift giving. In F.W. Rudmin and M.L. Richins (Eds.), Meaning, measure and morality of materialism (82-87). Provo, UT: Association for Consumer Research.

Megicks, P., Memery, J., \& Williams, J. (2008). Influences on ethical and socially responsible shopping: evidence from the UK grocery sector. Journal of Marketing Management, 24(5/6), 637659.

Menasco, M.B., \& Hawkins, D.I. (1978). A field test of the relationship between cognitive dissonance and state anxiety. Journal of Marketing Research, 15, 650-655.

Montgomery, C., \& Barnes, J.H. (1993). POSTDIS: A short rating scale for measuring postpurchase dissonance. Journal of Consumer Satisfaction, Dissatisfaction and Complaining Behavior, 6, 204-216.

Nisan, M. (1990). Moral balance: A model of how people arrive at moral decisions. In T. Wren (Ed.), The moral domain (pp. 283-314). Cambridge, MA: MIT Press.

O’Guinn, T.C., \& Faber, R.J. (1989). Compulsive buying: A phenomenological exploration. Journal Consumer Research, 16(2), 145-157.

Oliver, R.L. (1997). Satisfaction: A behavioral perspective on the consumer. New York: McGrawHill.

Oshikawa, S. (1969). Can cognitive dissonance theory explain consumer behaviour?. Journal of Marketing, 33, 44-49.

Oshikawa, S. (1970). Consumer pre-decisional conflict and post-decision dissonance. Behavioral Science, 15, 132-140.

Schroder, M.J.A., \& McEachern, M.G. (2004). Consumer value conflicts surrounding ethical food purchase decisions: a focus on animal welfare. International Journal of Consumer Studies, 28, $168-177$.

Shaw, D., Shiu, E., \& Clarke, I. (2000). The contribution of ethical obligation and self-identity to the theory of planned behaviour: an exploration of ethical consumers. Journal of Marketing Management, 16(8), 879-894.

Silfver, M. (2007). Coping with guilt and shame: A narrative approach. Journal of Moral Education, 36(2), 169-183. 
Slater, D., \& Miller, D. (2007). Moments and movements in the study of consumer culture: A discussion between Daniel Miller and Don Slater. Journal of Consumer Culture, 7, 5-23.

Smith, S.M., Haugtvedt, C. P., \& Petty, R.E. (1994). Attitudes and recycling: Does the measurement of affect enhance behavioral prediction? Psychology and Marketing, 11(4), 359-374.

Soutar, G.N., \& Sweeney, G.C. (2003). Are there cognitive dissonance segments?. Australian Journal of Management, 28(3), 227-249.

Starr, M.A. (2009). The social economics of ethical consumption: Theoretical considerations and empirical evidence. The Journal of Socio-Economics, 38, 916 -925.

Steenhaut, S., \& Kenhove, P. (2006). An empirical investigation of the relationships among a consumer' personal values, ethical ideology and ethical beliefs. Journal of Business Ethics, 64(2), 137-155.

Steinbruner, J.D. (1974) The cybernetic theory of decision. Princeton, NJ: Princeton University Press.

Sweeney, J.C., Hausknecht, D., \& Soutar, G.N. (2000). Cognitive dissonance after purchase: A multidimensional scale. Psychology and Marketing, 17(5), 369-385.

Szmigin, I., Carrigan, M., \& McEachern, M.G. (2007, July). Flexibility, dissonance and the conscious consumer. Paper presented at European Advances in Consumer Research, Milan.

Szmigin, I., Carrigan, M., \& McEachern, M.G. (2009). The conscious consumer: Taking a flexible approach to ethical behaviour. International Journal of Consumer Studies, 33, 224 -231.

Tangney, J.P., Stuewig, J., \& Mashek, D.J. (2007). Moral emotions and moral behaviour. Annual Review of Psychology, 58, 345-372.

Thompson, C.J. (1997). Interpreting consumers: A hermeneutical framework for deriving marketing insights from the texts of consumers' consumption stories. Journal of Marketing Research, 34, $438-456$.

Tracy, J.L., \& Robins, R.W. (2004). Putting the self into self-conscious emotions: A theoretical model. Psychological Inquiry, 15 (2), 103-125. 
Westbrook, R.A., \& Oliver, R.L. (1991). The dimensionality of consumption emotion patterns and consumer satisfaction. Journal of Consumer Research, 18(1), 84-91.

Williams, P., \& Aaker, J. (2002). Can mixed emotions peacefully co-exist?. Journal of Consumer Research, 28, 636-49.

Willis, K. (1990). In-depth interviews. In R. Birn, P. Hague, \& P. Vangelder (Eds.). A handbook of market research techniques (pp. 249-260). London: Kogan Page. 